\title{
THE USE OF NUMERICAL SIMULATIONS TO OBTAIN THE BASIC KNOWLEDGE ABOUT CASTING PROCESS OF HEAVY CIRCULAR INGOT
}

\author{
Vladislav KURKA, Marek VINDYŠ, Petr JONŠTA, Jaroslav PINDOR \\ MATERIÁLOVÝ A METALURGICKÝ VÝZKUM s.r.o., Ostrava, Czech Republic, EU \\ vladislav.kurka@mmvyzkum.cz
}

https://doi.org/10.37904/metal.2019.796

\begin{abstract}
During the casting of heavier ingots, internal porosity occurs during solidification due to shrinkage of the cast metal. Porosity, or non-metal-filled areas, is up to several centimeters inside large ingots. The present work deals with the study of physical-metallurgical parameters of casting a large circular ingot, leading to the elimination of porosity. Which was done using the numerical software Magma 5.4. In order to find the most suitable casting conditions, the planned experiment method called DoE was also partially used. Particular attention was paid to casting speed with investigation and finding the most suitable casting temperature. For the basic variant cast in the Magma software, an initial investigation of the temperature field and voltage state during the ingot cooling in the numerical software Forge NxT 2.1 was performed.
\end{abstract}

Keywords: Numerical, simulation, casting, solidification, Magma, Forge

\section{INTRODUCTION}

When casting heavier ingots weighing in the tens of tons, inner porosity occurs due to material shrinkage. Porosity or places inside large ingots not filled with metal are usually of a size of up to several centimetres [1], see Figure 1 and Figure 2. Porosity can be removed or eliminated in several ways, namely by adjusting the mould shape, head extension shape or its structure, and also naturally by the speed and temperature of casting.

The main aim was to find the most suitable casting temperature and casting speed for $12 t$ ingot casting. And for the basic variant cast in the Magma software, an initial investigation of the temperature field and voltage state during the ingot cooling in the numerical software Forge NxT 2.1 performs.
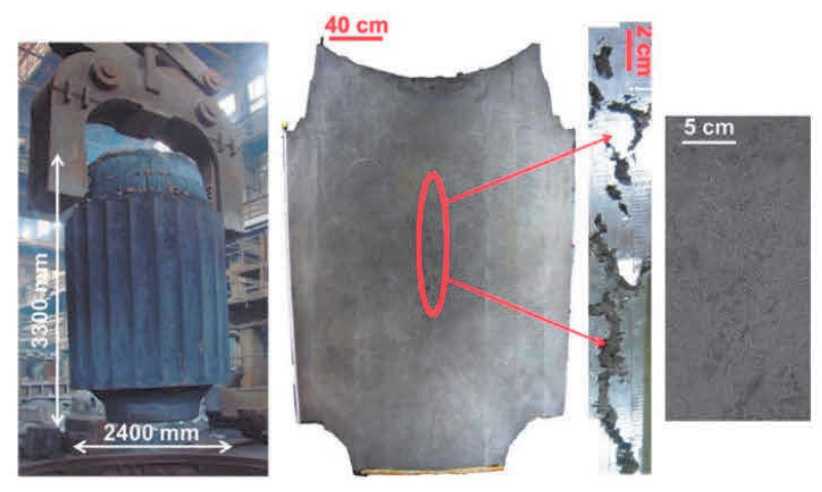

Figure 1 Porosity inside a heavy forging ingot, quality $30 \mathrm{Cr} 2 \mathrm{Ni4MoV}[1]$
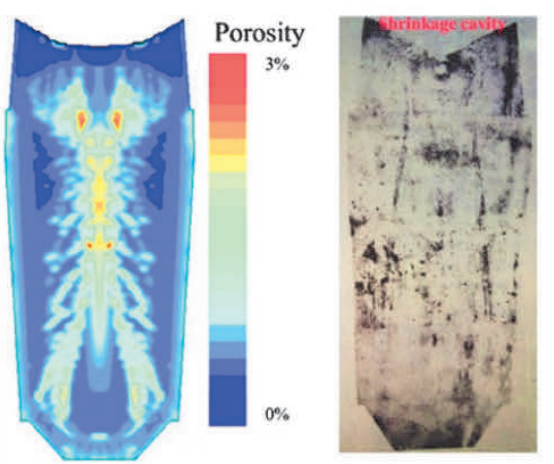

Figure 2 Porosity inside a large forging ingot, with $3.3 \%$ C [2]

Three types of porosity can occur in a cast. The first type is called microporosity or pores occurring in the central part of the ingot where it is very difficult to feed metal. The second type are cavities and the third one is macroporosity, which grows with decreasing pressure caused by shrinkage and grows in the interdendritic space [3], see Figure 3 which are mentioned by the author [4] and [5]. The authors tried to [6] successfully 
solve porosity through controlled heat conduction, which is, of course, a completely different type of solution to the issue.

a

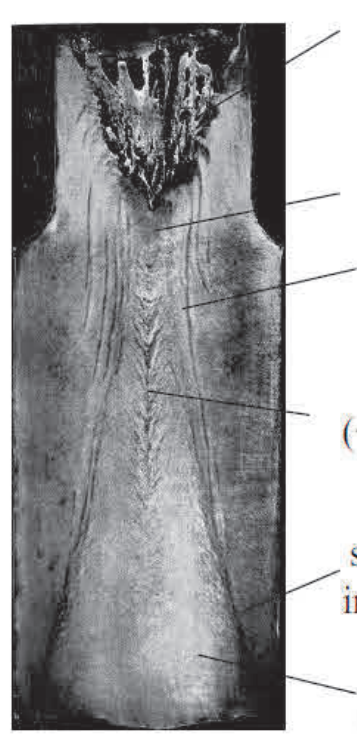

b

shrinkage

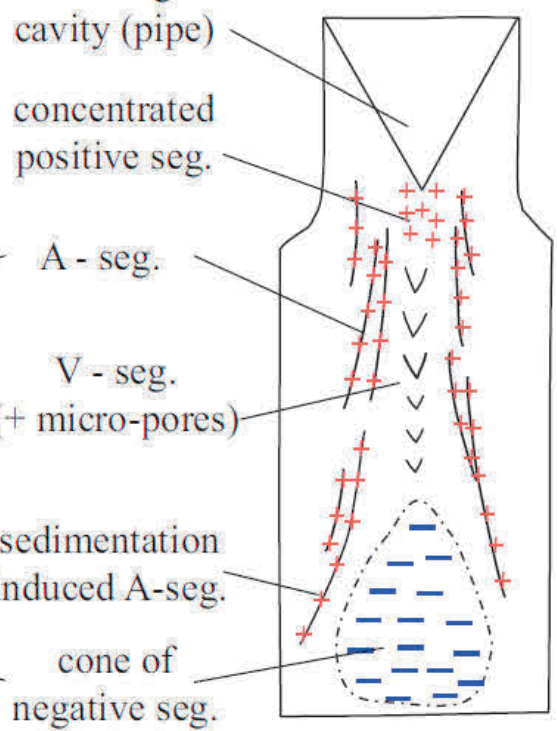

C

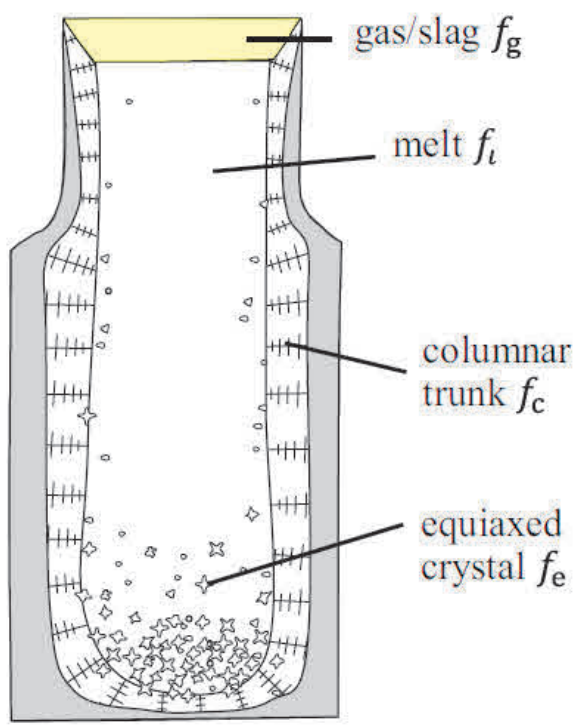

Figure 3 Scheme of solidification process and accompanying phenomena macro segregation and shrinkage, steel ingot weighing 10.5 tons with nominal composition $0.30 \%$ wt. C. a) Bauman's sulphur impression, b) schematic description of different types of macro segregation and shrinkage defects, c) a solidification process diagram and appropriate phases

\section{CASTING RESEARCH}

Within the solution to the given issue, an analysis was carried out of a circular ingot casting of the A type with a weight of $12 \mathrm{t}$ in Magma numerical software. The numerical solution was carried out on a casting set of 4 ingots weighing $12 \mathrm{t}$ each. Own simulations were carried out on $1 / 4$ of this casting set, thus on one ingot, see Figure 4. The outlined ingot was subsequently transferred to individual elements, see Figure 5. To make it clearer, the following evaluations include pictures containing all the variants of numerical simulations.

At the beginning, casting speed was analysed in dependence on the required temperature. Then, the most suitable speed of casting was chosen for which the most suitable casting temperature was found. First, a casting temperature of $1520^{\circ} \mathrm{C}$ was defined and a casting time selected. The numerical simulation defined in this way is the so-called basic and was marked "N.3". After performing numerical simulation "N.3", the examinations were carried out deviating from this variant by the casting speed of the ingot body and head extension compared to the variant:

- $\quad \mathrm{T} 75 \mathrm{H} 100.6$ - the body cast $25 \%$ more slowly and the head extension cast at the same speed.

- $\quad \mathrm{T} 125 \mathrm{H} 100.7$ - the body cast $25 \%$ more quickly and the head extension cast at the same speed.

- $\quad \mathrm{T} 100 \mathrm{H} 75.8$ - the body cast at the same speed and the head extension cast $25 \%$ more slowly,

- $\quad \mathrm{T} 100 \mathrm{H} 125.9$ - the body cast at the same speed and the head extension cast $25 \%$ more quickly.

It resulted from the numerical simulations that the $\mathrm{N} 3$ variant has the lowest microporosity, the $\mathrm{T} 75 \mathrm{H} 100.6$ version is the second, see Figure 6. Looking at Figure 7 we can see that both variants also have the highest temperature during the first filling of the space in the mould. We can conclude from the simulations in Figure 6 and Figure 7 that the change in the casting speed of the ingot body has a great influence on the improvement of microporosity at the same casting temperature. For this reason, a second examination of the 
best variant N.3 was carried out focusing on the impact of a change in microporosity when the casting speed changes and which differed from the N.3 variant as follows:

- $\quad \mathrm{T} 90 \mathrm{H} 100.11$ - the body cast $10 \%$ more slowly and the head extension cast at the same speed.

- $\mathrm{T} 110 \mathrm{H} 100.12$ - the body cast $10 \%$ more quickly and the head extension cast at the same speed.

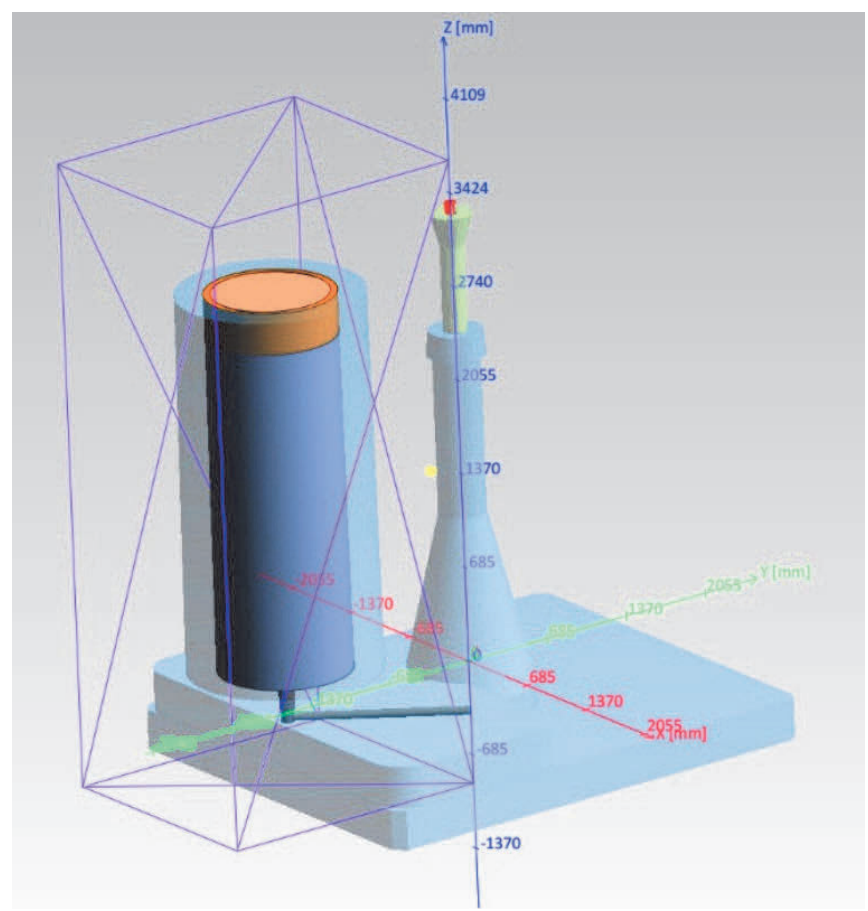

Figure 4 The geometric shape of the ingot, which was subsequently subjected to numerical simulation

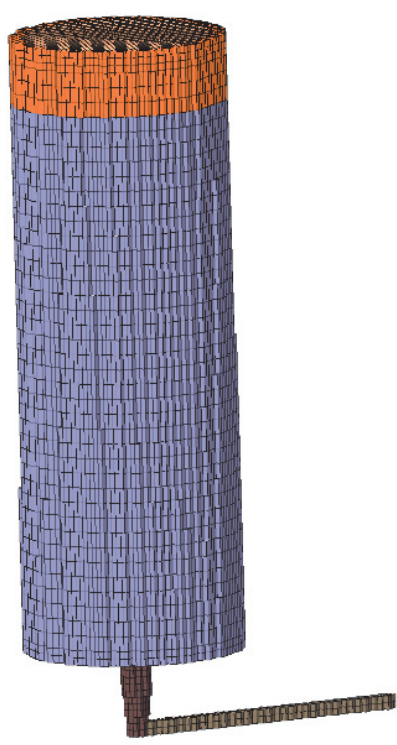

Figure 5 An ingot converted to elements that were subsequently numerically simulated

The numerical simulations given above were subjected to examination and compared with the results of the N.3 numerical simulation. Based on the evaluation of microporosity, the numerical simulation marked $\mathrm{T} 9 \mathrm{OH} 100.11$ has the best result. For the casting conditions given in the $\mathrm{T} 90 \mathrm{H} 100.11$ numerical simulation, the most suitable temperature of casting was looked in the range between $1515-1525{ }^{\circ} \mathrm{C}$ at the same casting speed.

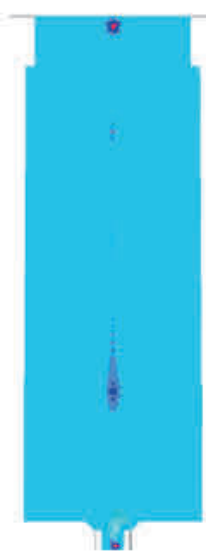

N.3

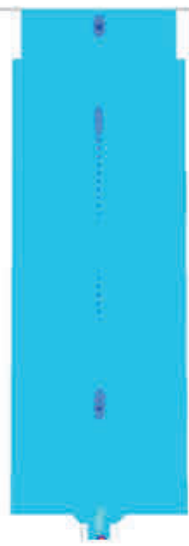

$\mathrm{T} 75 \mathrm{H} 100.6$

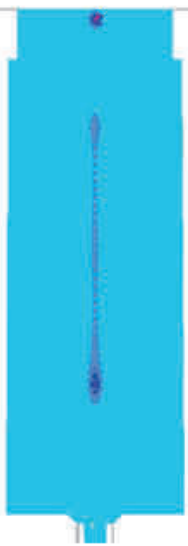

$\mathrm{T} 125 \mathrm{H} 100.7$

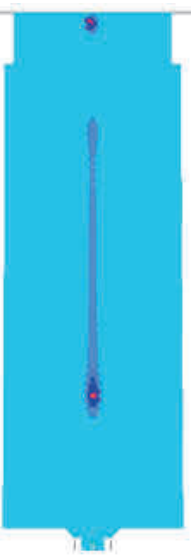

$\mathrm{T} 100 \mathrm{H} 75.8$
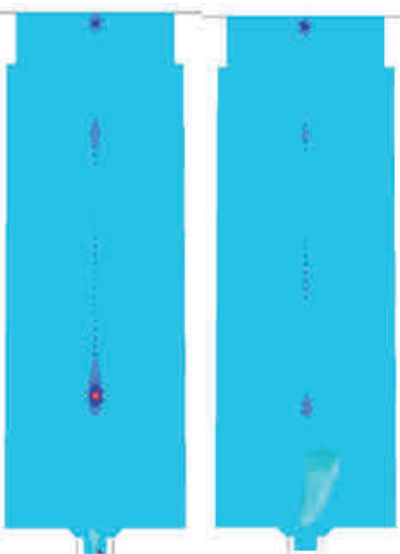

$\mathrm{T} 90 \mathrm{H} 100.11$

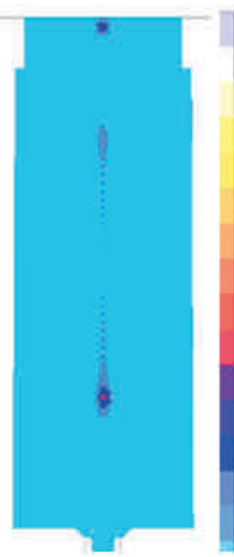

$\mathrm{T} 110 \mathrm{H} 100.12$

Figure 6 Microporosity in ingot after solidification, range 0-5\% 


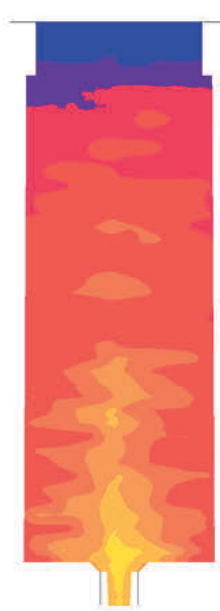

N.3

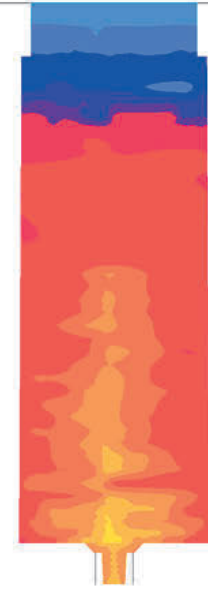

T75H100.6

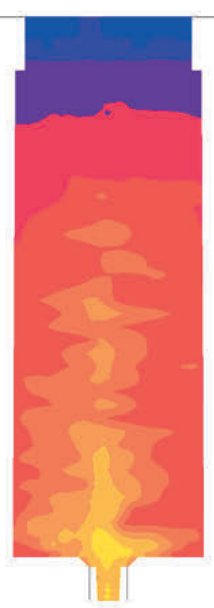

T125H100.7

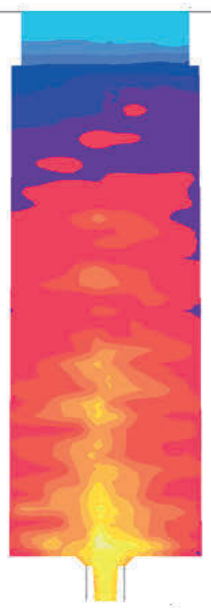

T100H75.8

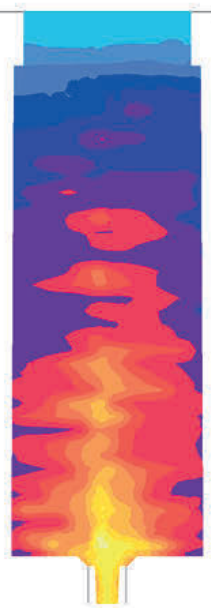

$\mathrm{T} 100 \mathrm{H} 125.9$

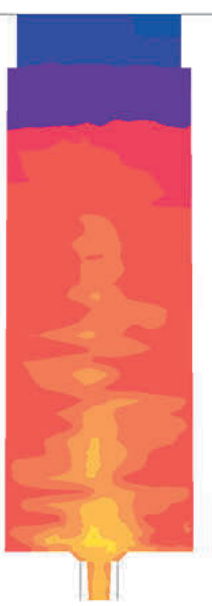

T90H100.1

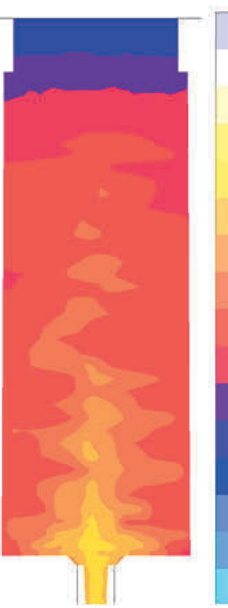

1520

1513

1506

1499

1492

1485

1478

1471

1464

1457

1450

Figure 7 Melt temperature, at first entry to the site, ranging between $1450-1520{ }^{\circ} \mathrm{C}$

The results of the numerical simulations performed were evaluated in this work mainly for microporosity in the T90H100.11 version with casting temperatures ranging between $1515-1525^{\circ} \mathrm{C}$, which are shown in Figure 8 . When looking at microporosity in Figure 8 it is obvious that the most suitable temperature is $1520{ }^{\circ} \mathrm{C}$ because it shows the lowest portion of microporosity inside the ingot body. This finding is also confirmed by the evaluation of numerical simulations using Magma software where it is obvious in 0 that the decrease in microporosity is greatest at a temperature of $1520^{\circ} \mathrm{C}$. Numerical simulations were also evaluated according to the course of solidification, see Figure 10, which shows that at a casting temperature of $1520{ }^{\circ} \mathrm{C}$ the melt solidifies the closest to the head extension. This indicates the maximum possibility of feeding the liquid metal from the head extension and also shows that microporosity in the ingot will not occur to a such a great extent as in the case of other ingots.

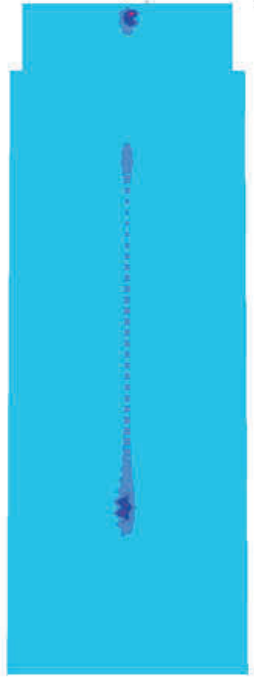

$1515^{\circ} \mathrm{C}$

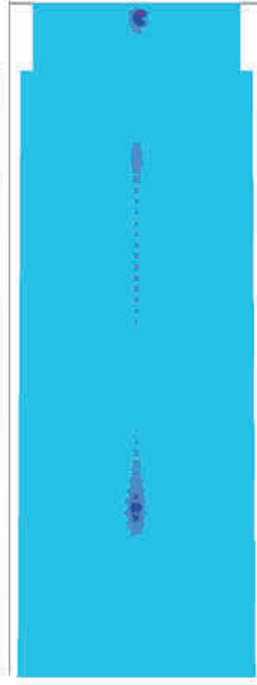

$1517.5^{\circ} \mathrm{C}$

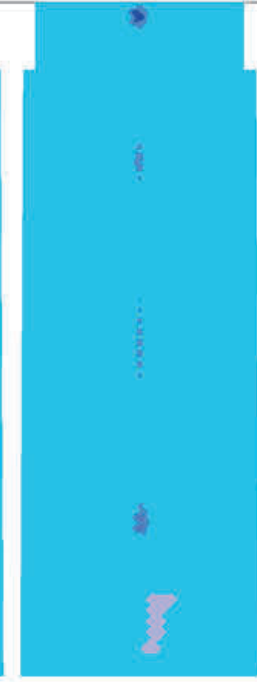

$1520^{\circ} \mathrm{C}$

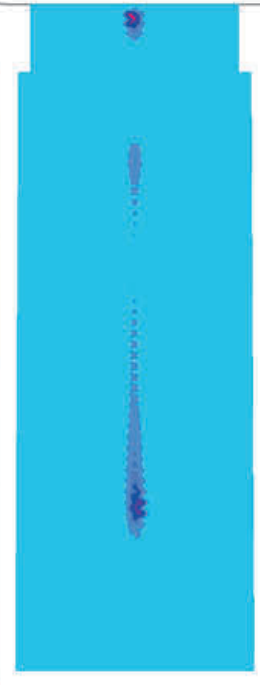

$1522.5^{\circ} \mathrm{C}$

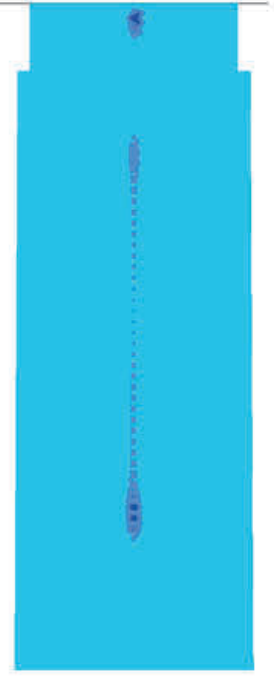

$1525^{\circ} \mathrm{C}$
(\%) 1525 1524 1523 1522 1521 1520 1519 1518 1517 1516 1515

Figure 8 Microporosity in T90H100.11 numerical simulation ingots, with casting temperatures $1515-1525{ }^{\circ} \mathrm{C}$, range $0-5 \%$ 


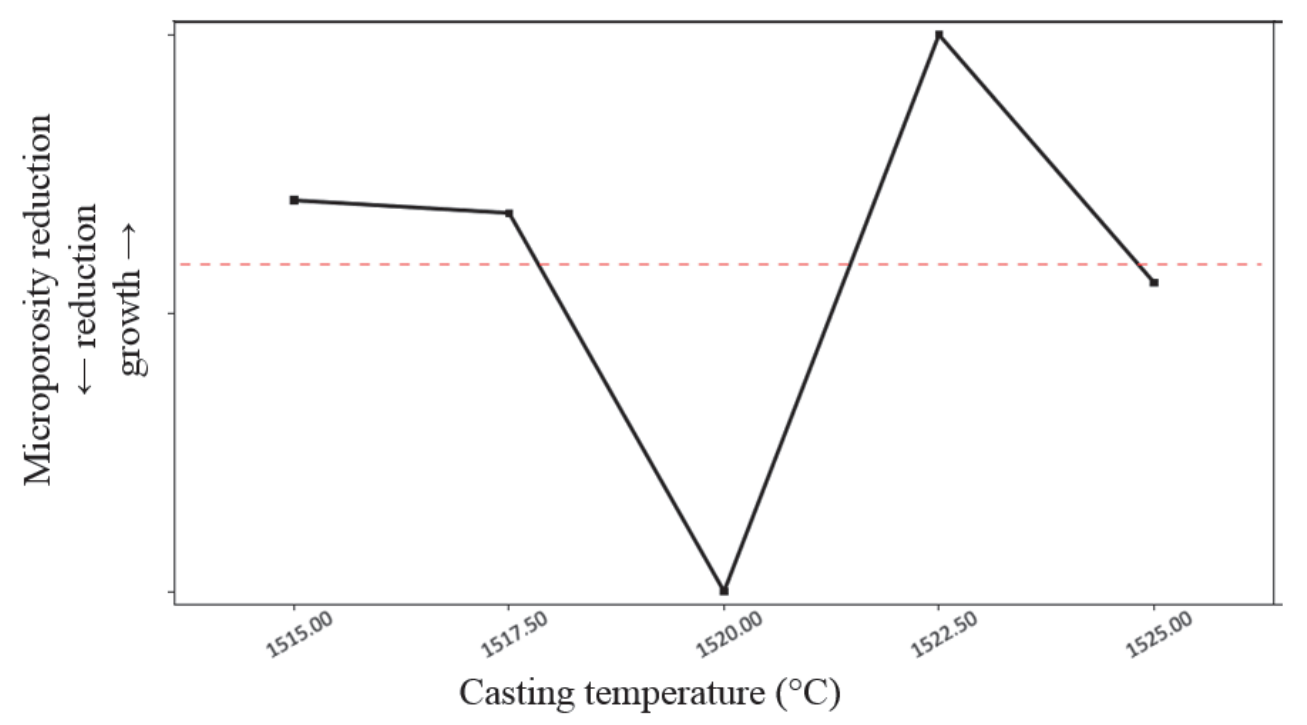

Figure 9 Effect of casting temperature on porosity reduction for $\mathrm{T} 90 \mathrm{H} 100.11$, with casting temperatures $1515-1525^{\circ} \mathrm{C}$

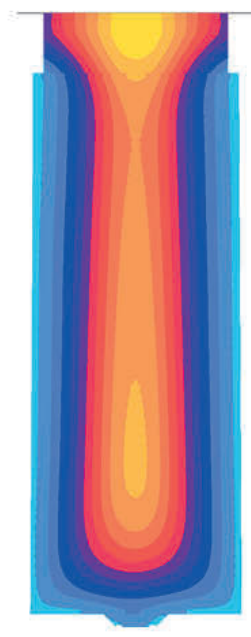

$1515^{\circ} \mathrm{C}$

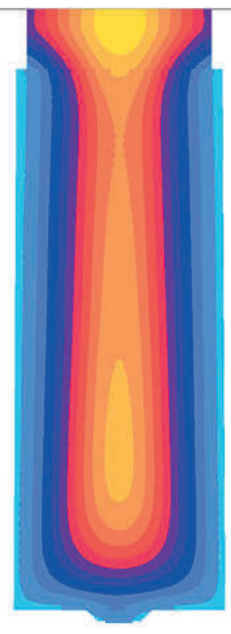

$1517.5^{\circ} \mathrm{C}$

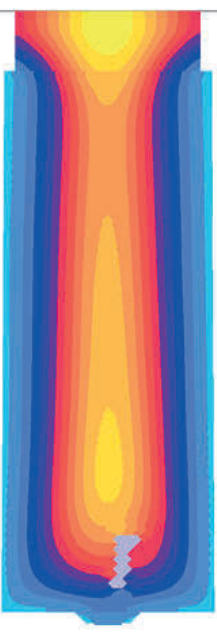

$1520^{\circ} \mathrm{C}$

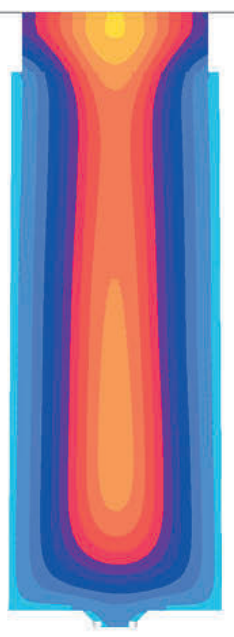

$1522.5^{\circ} \mathrm{C}$

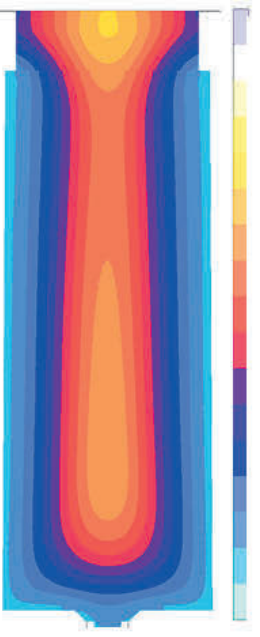

(s)

13000

11840

10680

9520

8360

7200

6040

4880

3720

2560

1400

Figure 10 Solidification time in individual parts of the ingot, T90H100.11, with casting temperatures 1515$1525^{\circ} \mathrm{C}$, range $1400-13000 \mathrm{~s}$

\section{SOLIDIFICATION RESEARCH}

Together with the numerical simulation of casting and solidification in Magma 5.4 software, an initial examination of the temperature field and stress state in the course of ingot cooling was carried out in Forge NxT 2.1 numerical software. The examination of the temperature field and stress state was carried out for the N.3 version. The set consisting of the ingot, head extension and casting pad designated for simulation was imported from Magma software right after the solidification of the entire ingot, thus after cooling of the entire ingot to the temperature of a solid. Non-transferred parts and parts from Magma were defined by the marginal conditions describing the thermal flux from the ingot to the surrounding elements (moulds) and the environment, and also by the marginal conditions including gravity, friction and expansion. 
Figure 11 shows the initial temperature field of the ingot and casting pad, N.3 version ranging from $171-1407^{\circ} \mathrm{C}$. At the beginning of cooling the head extension has a homogeneous temperature field of $1100{ }^{\circ} \mathrm{C}$ due to the disruption of geometry caused by solidification in Magma software - the creation of a shrinkage cavity during solidification.

Distribution of the temperature field in the ingot after 5 hours within a temperature range of $20-821^{\circ} \mathrm{C}$ is presented in Figure 12. On the left side of the figure, the ingot is cooled in the air; on the right side, the ingot is cooled in the mould. It applies to both types of ingot cooling that the hottest part of the ingot during solidification is in its central part. At the same moment, 5 hours after solidification, Figure 13 shows the distribution of effective stress (von Mises), which characterizes stress intensity. On the left side of the figure, the ingot is cooled in the air; on the right side, the ingot is cooled in the mould. It is obvious from the figure that the largest stress is in the ingot cooled in the air, namely in its surface layer at the footing and just under the head extension. This corresponds to the lowest stress in the ingot which is located in the ingot axis at the footing and just under the head extension.

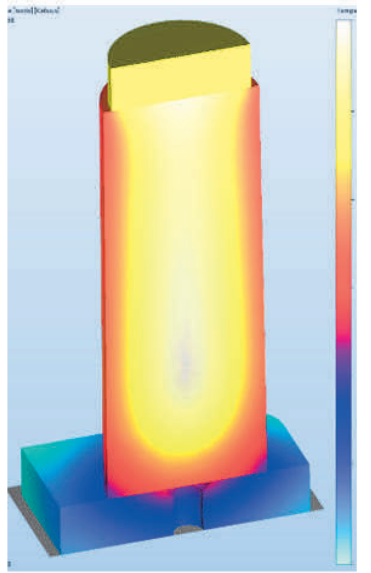

$\left({ }^{\circ} \mathrm{C}\right)$

1407

1283

1160

1036

913

789

665

542

418

295

171

Figure 11 Initial temperature field of ingot, version N.3, range $171-1407^{\circ} \mathrm{C}$

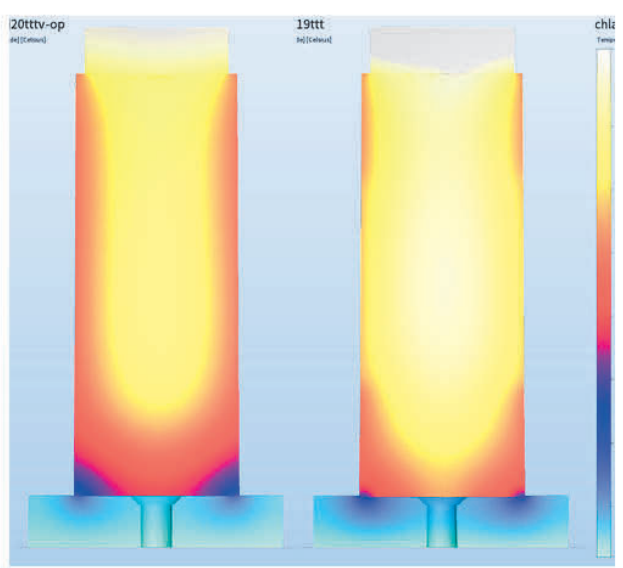

741

661

581

501

421

340

260

180

100

20
Figure 12 Temperature field of ingot after 5 hours of cooling (left in the air, right in the mould), version N.3, range $20-821^{\circ} \mathrm{C}$

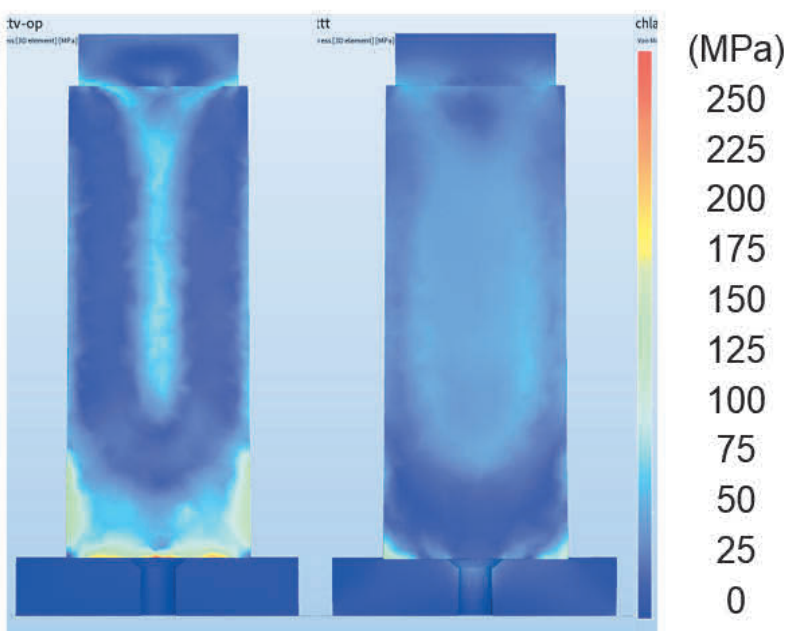

Figure 13 Distribution of effective stress in ingot, range 0-250 MPa

Effective stress distribution (von Mises) in ingot after 5 hours of cooling (left on the air, right in the mould), version N.3, logarithmic range $0-265 \mathrm{MPa}$ 


\section{CONCLUSION}

The submitted work presents basic knowledge from the area of large circular ingot casting obtained using Magma 5.4 numerical software. For the basic variant cast in Magma software, an initial examination was carried out of the temperature field and stress state during ingot cooling in numerical software Forge NxT 2.1.

It results from the performed numerical simulations of casting and solidification of the $12 \mathrm{t}$ circular ingot that as concerns reducing microporosity at the selected temperature of $1520{ }^{\circ} \mathrm{C}$, the most suitable numerical simulation chosen was that marked N.3, this being the originally suggested one. It has been proved that a change in speed of the ingot body casting has a greater positive influence on microporosity than a change in speed of head extension casting. To find out whether it really is the best variant, an examination of N.3 was carried out where the casting speed was decreased and increased in the ingot body by $10 \%$. It resulted from this that at the same speed of the head extension casting, it is more advantageous to cast the ingot $10 \%$ more slowly (version marked $\mathrm{T} 9 \mathrm{OH} 100.11$ ) than the initially proposed N.3. For this $\mathrm{T} 90 \mathrm{H} 100.11$ version, the most suitable casting temperature was $1520^{\circ} \mathrm{C}$.

It results from the performed primary examination of the numerical simulation of the temperature field and stress state in the ingot being cooled down in Forge software that when cooling the ingot in the air, large stress occurs in the surface layers of the ingot, namely up to $250 \mathrm{MPa}$ in the parts which solidified first.

\section{ACKNOWLEDGEMENTS}

The article was created thanks to project No. CZ.02.1.01/0.0/0.0/17_049/0008399 " Development of inter-sector cooperation of RMSTC with the application sphere in the field of advanced research and innovations of classical metal materials and technologies using modelling methods " from the EU and CR financial funds provided by the Operational Programme Research, Development and Education, Call 02_17_049 Long-Term Intersectoral Cooperation for ITI, Managing Authority: Czech Republic - Ministry of Education, Youth and Sports.

\section{REFERENCES}

[1] WANG, J., FU, P., LIU, H., LI, D., LI, Y. Shrinkage porosity criteria and optimized design of a 100-ton 30Cr2Ni4MoV forging ingot. Materials and Design. 2012, vol. 35, pp. 446-456.

[2] HONGHAO, G., FENGLI, R., JUN, L., XIUJUN, H., MINGXU, X., JIANGUO, L. Four-Phase Dendritic Model for the Prediction of Macrosegregation, Shrinkage Cavity, and Porosity in a 55-Ton Ingot. Metallurgical and materials transactions a. 2017, vol. 48A, pp. 1139-1150.

[3] WU, M., LUDWIG, A., KHARICHA, A. A four phase model for the macrosegregation and shrinkage cavity during solidification of steel ingot. Applied Mathematical Modelling. 2017, vol. 41, p. 102-120.

[4] CHVOJKA, J. Vady ingotů, $1^{\text {st }}$ ed. Praha: SNTL, 1968. 256 p.

[5] ŠMRHA, L. Tuhnutí a krystalizace ocelových ingotů, $1^{\text {st }}$ ed. Praha: SNTL, 1983. 308 p.

[6] PINDOR, J., KURKA, V., KOSŇOVSKÁ, J., ŠTEFANIŠINOVÁ, Š., SOCHA, L., PYSZKO, R. Effect of Cooling of the Ingot on its Macro-structural and Chemical Heterogeneity. Hutnicke listy. 2017, vol. 70, no. 3, pp. 47-57. ISSN 0018-8069. 